\title{
Assessment of Serum Cholesterol and Urea Levels of Smokers and Non Smokers.
}

\author{
Duru $\mathrm{BN}^{1}$, Okonkwo $\mathrm{PO}^{1}$, Magana $\mathrm{MN}^{2}$, Olawuyi $\mathrm{NO}^{2}$, Diddam $\mathrm{MO}^{2}$, Ujah \\ $\mathrm{AE}^{2}$, Okafor $\mathrm{PO}^{2}$, Salako $\mathrm{CY}^{3}$, Adeyanju $\mathrm{ON}^{3}$, Johnson $\mathrm{DO}^{3}$. \\ 1(Department Of Chemical Pathology, Federal College Of Veterinary and Medical Laboratory Technology, Nigeria) \\ 2(Department Of Chemical Pathology, Federal College Of Veterinary and Medical Laboratory Technology, Nigeria) \\ 2(Department Of Chemical Pathology, Ahmadu Bello University Zaria Nigeria) \\ 3(Department Of Haematology\&BGS, Federal College Of Veterinary and Medical Laboratory Technology, Nigeria) \\ 3(Department Of Molecular Biology, Federal College Of Veterinary and Medical Laboratory Technology, Nigeria)
}

\begin{abstract}
The wide spread and distressing heart disease related to smoking resulting from increased level in plasma total cholesterol was the focus of this work. The effect of smoking on serum cholesterol and urea levels of 160 subjects consisting of 80 smokers and 80 nonsmokers (control) was investigated. Total cholesterol and urea levels were determined by enzymatic colorimetric end point (CHOD-PAP) increasing reaction (diagnostic reagent for quantitative invitro determination of cholesterol in serum or plasma on photometric system) and modified Berthelot methods respectively. The mean cholesterol levels were $7.35+0.27 \mathrm{mmol} / \mathrm{l}$ and $3.34+1.99 \mathrm{mmol} / \mathrm{l}$ for the smokers and nonsmokers respectively while the mean serum urea level were $9.30+1.14 \mathrm{mmol} / \mathrm{l}$ and $3.85+0.04 \mathrm{mmol} / \mathrm{l}$ for the smokers and nonsmokers respectively. There was statistical significant difference in the mean cholesterol and urea levels between smokers and nonsmokers (control) using the student "d"tests. The work showed that the mean serum total cholesterol and urea concentrations were higher for smokers than nonsmokers indicating that smokers are predisposed to cardiovascular disease and possible renal problem.
\end{abstract}

Key Words: Cholesterol, Nonsmokers, Smokers, Peer pressure, Risky behavior, Urea.

\section{Introduction}

Tobacco is an agricultural products from the fresh leaves of the plant of the genus nicotiana figure 1 and commercially tobacco is available in dried, cured, and natural forms [1]

The composition of cigarette smoke include nicotine, carbon monoxide and tar and tar is known to Contain up to 400 or more chemicals of which over 60 are known to cause cancer[2][3].

A Persons increased risk of contacting diseases is directly proportional to the length of time that a person continues to smoke as well as the amount smoked. Physiologic manifestation in tobacco users includes stains on the $2^{\text {nd }}$ and $3^{\text {rd }}$ finger figure2,alertness , memory as well as mild euphoria in first time or irregular users while for chronic users, the nicotine simply relieves the symptoms of withdrawal such as confusion ,insomnia, restlessness, anxiety others [4].

The main health risk in tobacco pertain to diseases of the cardiovascular system like myocardial infarction (heart attack), diseases of the respiratory tract such as chronic obstructive pulmonary diseases, asthma, emphysema and many forms of cancer figure3, particularly lung cancer, kidney cancer [39] cancer of the larynx and head and neck, breast cancer, bladder cancer [5], cancer of the esophagus, cancer of the pancreas and stomach cancer [6][7].

There is some evidence suggesting a small increased risk of myeloid leukemia, squamous cell sinonasal cancer, liver cancer, colorectal cancer, cancers of the gallbladder, the adrenal gland, the small intestine, and various childhood cancers. Recent studies have established a stronger relationship between tobacco smoke, including secondhand smoke, and cervical cancer in women [8][9].

In the body, tobacco smoking in particular nicotine causes the release of adrenal due to effect on the brain thus increasing heart rate and blood pressure leading to shallow and rapid breathing [10].

Smoking also leads to blocking of insulin release hence increasing the concentration of blood glucose and the resulting increase on the metabolic rate brings the weight loss found in the Smokers [11][].

Another effect of Tobacco is on the Oxygen carrying capacity of the blood or red cell, Carbon monoxide has many times greater affinity for hemoglobin more than Oxygen so carboxyl hemoglobin is readily formed thus reducing the distribution and Oxygen carry capacity of the blood by about 12 to $15 \%$ [12]. It has also been documented that nicotine is also excreted in the milk of lactating women who smoke and thus can be taken even by the baby as mammary milk of heavy Smokers may contain $0.5 \mathrm{mg}$ of nicotine per litre of milk $[13][14][15]$. 
Cholesterol is affected by tobacco smoking leading to various conditions associated with cardiovascular disease, cerebrovascular accident and coronary artery disease. This condition arises as carbon monoxide in the blood of cigarette smokers may damage the endothelium and accelerate the entry of cholesterol from plasma into the walls of the coronary artery which accumulation of cholesterol ultimately leads to blockage of the coronary artery resulting to arthrosclerosis[16][17].

In addition also due tobacco usage, nicotine can cause or act as a vasoconstrictor there by decreasing the blood supply to the heart muscle apart from increasing fatty acid deposit on the walls of the inner walls of the arteries of the heart[18][17].

The outbreak of certain type of diseases and infections has been found to affect smokers more than nom smokers. A study of an outbreak of (H1N1) influenza in an Israeli military unit of 336 healthy young men to determine the relation of cigarette smoking to the incidence of clinically apparent influenza revealed that, of 168 smokers, 68.5 percent had influenza, as compared with 47.2 percent of nonsmokers. Influenza was also more severe in the smokers; 50.6 percent of the smokers lost work days or required bed rest, or both, as compared with 30.1 percent of the nonsmokers [19][20].

Smoking seems to cause a higher relative influenza-risk in older populations than in younger populations. In a prospective study of community-dwelling people 60-90 years of age, during 1993, of unimmunized people $23 \%$ of smokers had clinical influenza as compared with $6 \%$ of non-smokers [21].

Also some serious oral infection has been found to be exclusive associated with cigarette smoking. In 1998, The National Institutes of Health, through the National Cancer Institute, determined that "cigar smoking causes a variety of cancers including cancers of the oral cavity (lip, tongue, mouth, throat), esophagus, larynx, and lung [22][23], Pipe smoking involves significant health risks[24][25] particularly oral cancer[26][27]. Roughly half of periodontis or inflammation around the teeth cases is attributed to current or former smoking. Smokeless tobacco causes gingival recession and white mucosal lesions. Up to $90 \%$ of periodontitis patients who are not helped by common modes of treatment are smokers. Smokers have significantly greater loss of bone height than nonsmokers, and the trend can be extended to pipe smokers to have more bone loss than nonsmokers. Smoking has been proven to be an important factor in the staining of teeth [28][29] . Halitosis or bad breath is common among tobacco smokers. Tooth loss has been shown to be 2 to 3 times higher in smokers than in non-smokers[30].

Smoking more than 20 cigarettes a day increases the risk of tuberculosis by two to four times, and being a current smoker has been linked to a fourfold increase in the risk of invasive pneumococcal disease. It is believed that smoking increases the risk of these and other pulmonary and respiratory tract infections both through structural damage and through effects on the immune system. The effects on the immune system include an increase in CD4+ cell production attributable to nicotine, which has tentatively been linked to increased HIV susceptibility[31][32].

Nicotine becomes absorbed from the respiratory tract through the mouth, tissue and skin and metabolized in liver, kidney, lung but with the lung metabolizing a major portion of inhaled nicotine from tobacco smoking. However whether inhaled or administered by injection, the half life is about two hours, with the kidney eliminating both nicotine and its byproducts usually via acid $\mathrm{PH}[24][25]$.

Tobacco smoking also leads to increasing blood urea level because of its damaging effect on the kidney and liver cells dues largely to contamination of blood by the constituents of the tobacco Smoke. In addition to increasing the risk of kidney cancer, smoking can also contribute to additional renal damage. Smokers are at a significantly increased risk for chronic kidney disease than non-smokers.[33][34]A history of smoking encourages the progression of diabetic nephropathy[35].

\subsection{Justification}

Smoking will continue to attract public health attention and cigarettes smoking in under developed Countries tend to increase vulnerability to tobacco-related disease in these regions as well as damages to organs and tissues of the body such as the kidney and the respiratory system among other $\mathrm{s}$ which can be assessed by the level of cholesterol and urea levels in both Smokers and non Smokers.

\subsection{Aim}

1 To determined the Serum cholesterol and Urea in both Smokers and non Smokers.

2 To compare the results obtained from the two groups.

3 To create the awareness on the need to stem the spread of smoking among people. 
Figure1.

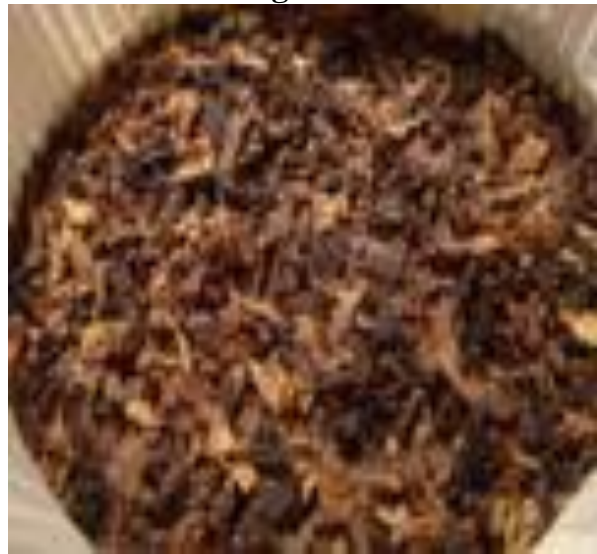

Nicotiana ( Nicotiana tabacum)

Figure2.

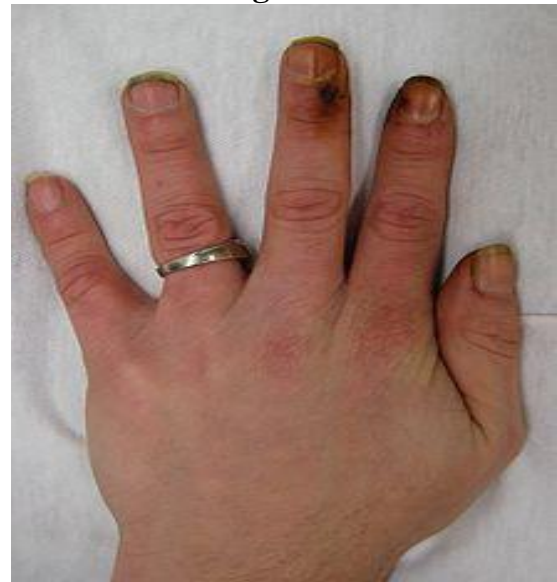

Tobacco stains on primarily the 2nd and 3rd fingers in a heavy smoker.

Figure3.

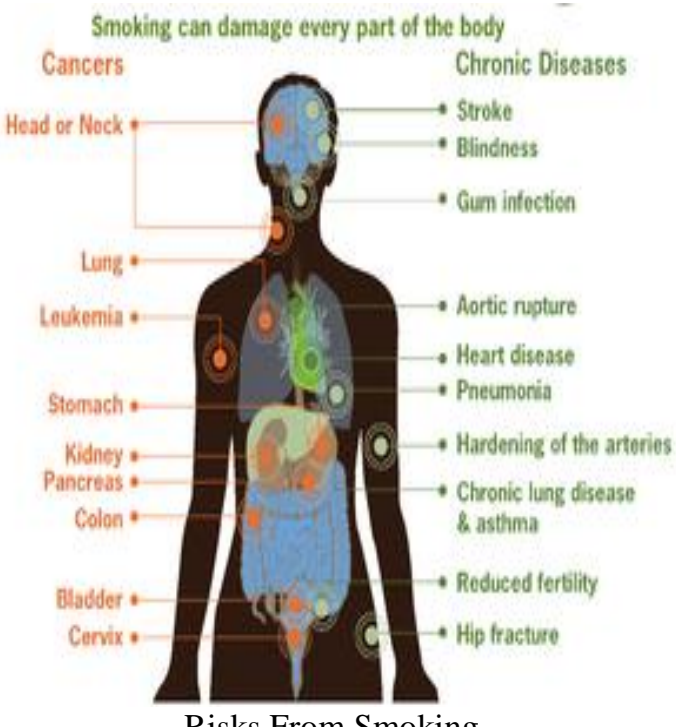

Risks From Smoking 


\section{Materials And Method.}

\subsection{Study Subjects/Collection/Analysis.}

A total of 160 randomly selected subjects consisting of 80 smokers and 80 non smokers were used as contacts. All subject were males students in Ribah, Danko Local government area of Kebbi State and do not have any history of diabetes mellitus, however each smoker has been smoking for over ten years. The blood supply used for this work were collected through vene puncture from the anticubital vein of the forearm using fresh disposable hypodermic syringe and needles, after sterilization of the forearm with cotton wool soaked in $70 \%$ alcohol.5ml of blood was collected from each subjects and transferred to a clean dry centrifuge tube, allowed to clot and retract and centrifuged at $3000 \mathrm{rpm}$ for 5 minutes. The serum was collected using grease free Pasteur pipette and labeled appropriately. Serum total cholesterol was determined based on the procedure given by fortress reagent kit manufacturer for total cholesterol (CHOD-PAP) while urea was determined by Berthelot Method.

III. Results

Table1. Shown the mean and standard deviation of Serum cholesterol of Smokers and non smokers (Control)

\begin{tabular}{lllll}
\hline Source & Biochemical Parameter & No Of samples & Mean & Standard deviation \\
\hline Smokers & Cholesterol & 80 & 7.35 & 0.27 \\
Non Smokers & Cholesterol & 80 & 3.34 & 1.99 \\
\hline
\end{tabular}

Table2. Shown the mean and standard deviation of Urea of Smokers and Control

\begin{tabular}{lllll}
\hline Source & Biochemical Parameter & No of Sample & Mean & Standard Deviation \\
\hline Smokers & Urea & 80 & 9.30 & 1.14 \\
Non Smokers & Urea & 80 & 3.80 & 0.04 \\
\hline
\end{tabular}

Table3. Shows Statistical test Comparing The Mean Serum Cholesterol and Urea of Smokers and Non smokers (Control)

\begin{tabular}{|c|c|c|c|c|c|}
\hline $\begin{array}{c}\text { Biochemical } \\
\text { parameters }\end{array}$ & Degree Of Freedom & $\begin{array}{rc}\begin{array}{r}\text { Calculated } \\
\text { value }\end{array} & \text { d- } \\
\end{array}$ & $\begin{array}{cc}\text { Tabulated } & \text { d- } \\
\text { Value } & \\
\end{array}$ & $\begin{array}{c}\text { Probability } \\
\text { Level }\end{array}$ & Remarks \\
\hline Cholesterol & 158 & 17.39 & 1.96 & $\mathrm{P}<0.05$ & Significant \\
\hline Urea & 158 & 34.44 & 1.96 & $\mathrm{P}<0.05$ & significant \\
\hline
\end{tabular}

Table4. Shows Number and Percentage Value of Smokers Based on Their Reasons for Smoking.

\begin{tabular}{ccc}
\hline Reasons & Number(n) & Percentage (\%) \\
\hline Peer Pressure & 26 & 32.50 \\
Social Acceptance & 15 & 18.75 \\
Stress/Anxiety & 5 & 6.25 \\
Advertisement & 5 & 6.25 \\
Whether (cold) & 5 & 6.25 \\
Smoking Parent/guardian & 6 & 7.50 \\
Role Model & 5 & 6.25 \\
\hline
\end{tabular}

\section{Discussion}

The health effects of tobacco are the circumstances, mechanisms, and factors of tobacco consumption on human health. Epidemiological research has been focused primarily on cigarette tobacco smoking, which has been studied more extensively than any other form of consumption [36][37].

Tobacco is the single greatest cause of preventable death globally. Tobacco use leads most commonly to diseases affecting the heart, liver and lungs, with smoking being a major risk factor for heart attacks, strokes, chronic obstructive pulmonary disease (copd) (including emphysema and chronic bronchitis), and cancer (particularly lung cancer), cancers of the larynx and mouth, and pancreatic cancer). It also causes peripheral vascular disease and hypertension [10]. in this study, it was observed that there was a high cholesterol in the blood of smokers. Table1. Inhalation of tobacco smoke causes several immediate responses within the heart and blood vessels. Within one minute the heart rate begins to rise, increasing by as much as 30 percent during the first 10 minutes of smoking. Carbon monoxide in tobacco smoke exerts its negative effects by reducing the blood's ability to carry oxygen. Both of these conditions can become permanent with prolonged use of cigarettes [38]

Smoking also increases the chance of heart disease, stroke, atherosclerosis, and peripheral vascular disease. Several ingredients of tobacco lead to the narrowing of blood vessels, increasing the likelihood of a 
blockage, and thus a heart attack, or stroke. According to a study by an international team of researchers, people under 40 are five times more likely to have a heart attack if they smoke [38]. The mean cholesterol of smokers and non smokers were found to be $7.35 \pm 0.27 \mathrm{mmol} / 1$ and $3.34 \pm 1.99 \mathrm{mmol} / 1 \mathrm{respectively} \mathrm{(Tables} 1$ and 2).

Comparism of the mean serum levels of cholesterol in smokers and non smokers carried out using the students -d-test indicated a significant difference $\mathrm{p}<0.05$ (Table3). This finding agree with the work of kershabaum et al 1976 and American heart association [16] which reported an increased free fatty acid level by $35 \mathrm{mmol} / \mathrm{l}$ in smokers. When fatty acids are released at once they are bound to albumin and transported to the tissue especially the liver, thus nicotine increases the plasma triglyceride and very low density lipoprotein cholesterol leading to a rise in the level of VLDL cholesterol cumulative effect the overall increase in cholesterol level of the body [16].

Smoking tends to increase blood cholesterol levels. Furthermore, the ratio of high-density lipoprotein (the "good" cholesterol) to low-density lipoprotein (the "bad" cholesterol) tends to be lower in smokers compared to non-smokers. Smoking also raises the levels of fibrinogen and increases platelet production (both involved in blood clotting) which makes the blood viscous. Carbon monoxide binds to hemoglobin (the oxygencarrying component in red blood cells), resulting in a much stable complex than hemoglobin bound with oxygen or carbon dioxide - the result is permanent loss of blood cell functionality. Blood cells are naturally recycled after a certain period of time, allowing for the creation of new, functional erythrocytes. However, if carbon monoxide exposure reaches a certain point before they can be recycled, hypoxia (and later death) occurs. All these factors make smokers more at risk of developing various forms of arteriosclerosis. As the arteriosclerosis progresses, blood flows less easily through rigid and narrowed blood vessels, making the blood more likely to form a thrombosis (clot). Sudden blockage of a blood vessel may lead to an infarction (stroke) [10].

Urea in both smokers and control were found to be $9.30 \pm 0.14$ and $3.85 \pm 0.04$ respectively, (Tables 1 and 2). Comparism of the mean serum urea of smokers and non smokers also showed a significant difference $(\mathrm{p}<0.05)$ (Table 3). Tobacco smoking have been known to damage the liver and kidney due to the toxic action of the constituents which causes cancer as well as degeneration of the cells of the kidney and liver [39][40] .

In addition to increasing the risk of kidney cancer, smoking can also contribute to additional renal damage. Smokers are at a significantly increased risk for chronic kidney disease than non-smokers [41] . A history of smoking encourages the progression of diabetic nephropathy [42]

This work also revealed various reasons why people smoke, an indication that smoking and health damage could also be reduced by considering these factors (Table 4). A large part of the reason such as peer pressure comes under scrutiny is that one of the groups most likely to begin smoking -- young teenagers are also the most susceptible to peer pressure. Although it's a little more complex and has the potential to affect more than just peer-pressure-sensitive tweens and teens. In short, social rewards are the "gifts" people feel they receive when participating in a group activity. Most often, this means some form of acceptance. Adults in countries where smoking is frowned upon are familiar with the no-smoking signs, designated smoking areas and general restrictions on their ability to smoke when and where they wish. But these rules -- legal, physical and social -- can offer tempting lines to cross for young people who tend toward risk-taking behavior[16][43].

The relationship between parents smoking and their children smoking is blunt: children of active smokers are more likely to start smoking than children of nonsmokers, or children of parents who quit smoking. According to some studies, a parent's choice to smoke can more than double the odds that the child will smoke[44] in addition, medical genetic research is beginning to suggest, too, that addictions - including addiction to nicotine the effective ingredient in tobacco products -- may have a genetic component [45][43].

\section{Conclusion}

smoking will continue to attract public attention due to its public health importance and particularly because of the various harmful health effects associated with it which may require more proactive approach from government notably in the area of legislation, together with parents, other well meaning individuals as well as non-governmental organizations, the print and television media so as to bring to bear the need to for the populace to try their best to stop or reduce smoking and associated health problems which are avoidable.

\section{Acknowledgement}

We sincerely thank the people of Ribbah in Danko local government area of Kebbi State for their support and willingness. We also thank the staff of Kebbi State specialist Hospital where the analysis of this work was done. We also thank Mr. A. A. Chukwuedo for his contribution to the work and mr Tolu for the computer type setting. 


\section{References}

[1]. Loren Stein. "Pipe Smoking". A Healthy Me!. Retrieved 2008-01-04.Commission on Life Sciences. "Environmental Tobacco Smoke: Measuring Exposures and Assessing Health Effects (1986)". Retrieved 2008-01-04.

[2]. Cui Y, Miller AB, Rohan TE (2006). "Cigarette smoking and breast cancer risk: update of a prospective cohort study". Breast Cancer Research and Treatment 100 (3): 293-299. doi:10.1007/s10549-006-9255-3. PMID 16773435.

[3]. Routh HB, Bhowmik KR, Parish JL, Parish LC. (1998). Historical Aspects of Tobacco Use and Smoking. Clinics in Dermatology, 16(5):539-544

[4]. Gupta R.,MD,MPH;Hitinder Guom,MD;John R.Barthlomew,MD(2005):Smokeless tobacco and cardiovascular risk. Arch intern med.164;1845-1849.

[5]. Thompson Gale (2006):Nicotine action and the physiology of smoking from wond of Anatomy and Physiology.c 2005-2006

[6]. Boffetta P (2008). "Tobacco smoking and risk of bladder cancer". Scandinavian Journal of Urology and Nephrology 42 (218): 45 54. doi:10.1080/03008880802283664. PMID 18815916

[7]. Sajid KM, Chaouachi K, Mahmood R (2008). "Hookah smoking and cancer: carcinoembryonic antigen (CEA) levels in exclusive/ever hookah smokers". Harm Reduct J 5: 19. doi:10.1186/1477-7517-5-19. PMC 2438352. PMID 18501010.

[8]. Institute of Medicine. Secondhand Smoke Exposure and Cardiovascular Effects: Making Sense of the Evidence. E⿱⺈ Washington: National Academy of Sciences, Institute of Medicine, 2009.

[9]. Office of the US Surgeon General.(2004)The Health Consequences of Smoking:A Reportof the Surgeon General. Centers for Disease Control and Prevention (CDC), Office on Smoking and Health.Available at http://www.surgeongeneral.gov/library/smokingconsequences/.Accessed October 17, 2005

[10]. Narkiewicz K, Kjeldsen SE, Hedner T (2005). "Is smoking a causative factor of hypertension?". Blood Pressure 14 (2): 69-71. doi:10.1080/08037050510034202. PMID 16036482.

[11]. Esson, Katharine M. (2004).The Millennium development goals and tobacco control: an opportunity for global partnership. ed. World Health Organization: 48

[12]. Fould,J.Ramson,Bunce,M.,and Fagerstron,K.,(2003):Effect of smokeless tobacco on smoking and Public health in Sweden.Tob.Control,12(4):349-359.

[13]. History of tobacco(2005);www.tobacco.YAIS.com/composition Ibeh CC, Ele PU. (2003). Prevalence of cigarette smoking in young Nigerian females. Afr J Med Med Sci; 32(4):335-8

[14]. U.S. Department of Health and Human Services. Women and Smoking: A Report of the Surgeon General. Rockville (MD): U.S Department of Health and Human Services, Public Health Service, Office of the Surgeon General, 2001

[15]. Ward C, Lewis S, Coleman T (2007). "Prevalence of maternal smoking and environmental tobacco smoke exposure during pregnancy and impact on birth weight: retrospective study using Millennium Cohort". BMC Public Health 7: 81. doi:10.1186/14712458-7-81. PMC 1884144. PMID 17506887.

[16]. American Heart Association. "Cigarette Smoking Statistics." 2008. National Center for Health Statistics. (May 2, 2011)http://www.americanheart.org/presenter.jhtml?identifier=4559

[17]. Vanni H, Kazeros A, Wang R, Harvey BG, Ferris B, De BP, Carolan BJ, Hübner RH, O'Connor TP, Crystal RG (2009). "Cigarette smoking induces overexpression of a fat-depleting gene AZGP1 in the human". Chest 135 (5): 1197-1208. doi:10.1378/chest.081024. PMC 2679098. PMID 19188554

[18]. Finklea JF, Sandifer SH, Smith DD (November 1969). "Cigarette smoking and epidemic influenza". Am. J. Epidemiol. 90 (5): 390 9. PMID 5356947

[19]. Kark JD, Lebiush M (May 1981). "Smoking and epidemic influenza-like illness in female military recruits: a brief survey". Am J Public Health 71 (5): 530-2. doi:10.2105/AJPH.71.5.530. PMC 1619723. PMID 7212144.

[20]. Nicholson KG, Kent J, Hammersley V (August 1999). "Influenza A among community-dwelling elderly persons in Leicestershire during winter 1993-4; cigarette smoking as a risk factor and the efficacy of influenza vaccination". Epidemiol. Infect. 123 (1): 1038. doi:10.1017/S095026889900271X. PMC 2810733. PMID 10487646.

[21]. Johnson GK, Slach NA (2001). "Impact of tobacco use on periodontal status". Journal of dental education 65 (4): 313-21. PMID 11336116.

[22]. Reibel J (2003). "Tobacco and oral diseases. Update on the evidence, with recommendations". Medical principles and practice : international journal of the Kuwait University, Health Science Centre 12 Suppl 1: 22-32. doi:10.1159/000069845. PMID 12707498

[23]. Yacoub R, Habib H, Lahdo A, Al Ali R, Varjabedian L, Atalla G, Kassis Akl N, Aldakheel S, Alahdab S, Albitar S (2010). "Association between smoking and chronic kidney disease: a case control study". BMC Public Health 10: 731. doi:10.1186/14712458-10-731. PMC 3004836. PMID 21108832.

[24]. Yusuf,O.A,Swart,J.J.,and Pickworth,W.B (2004)Nicotine delivery capabilities of smokeless tobacco products and implications for control of tobacco dependence in south Africa.Tob.Control,13(2)186-189.

[25]. Johnson GK, Slach NA (2001). "Impact of tobacco use on periodontal status". Journal of dental education 65 (4): $313-21$. PMID 11336116

[26]. Reibel J (2003). "Tobacco and oral diseases. Update on the evidence, with recommendations". Medical principles and practice : international journal of the Kuwait University, Health Science Centre 12 Suppl 1: 22-32. doi:10.1159/000069845. PMID 12707498

[27]. Al-Bayaty FH, Wahid NA, Bulgiba AM (2007). "Tooth mortality in smokers and nonsmokers in a selected population in Sana'a Yemen". Journal of Periodontal Research 0 (1): 070508213437002. doi:10.1111/j.1600-0765.2007.00988.x. PMID 18230101. edit

[28]. Davies PD, Yew WW, Ganguly D, Davidow AL, Reichman LB, Dheda K, Rook GA (2006). "Smoking and tuberculosis: the epidemiological association and immunopathogenesis". Transactions of the Royal Society of Tropical Medicine and Hygiene 100 (4): 291-298. doi:10.1016/j.trstmh.2005.06.034. PMID 16325875.

[29]. International union against tuberculosis and lung diseases .Fact and figure on tobacco use Available at: http://www.iuatld.org. Accessed April 11, 2008

[30]. Lipworth L, Tarone RE, McLaughlin JK (2006). "The Epidemiology of Renal Cell Carcinoma". The Journal of Urology 176 (6 Pt 1): 2353-2358. doi:10.1016/j.juro.2006.07.130. PMID 17085101.

[31]. Sawicki PT, Didjurgeit U, Mühlhauser I, Bender R, Heinemann L, Berger M (February 1994). "Smoking is associated with progression of diabetic nephropathy". Diabetes Care 17 (2): 126-31. doi:10.2337/diacare.17.2.126. PMID 8137682.

[32]. American Cancer Society (2005), www.cancer.org

[33]. Odeyemi KA, Osibogun A, Akinsete AO,Sadiq L: The Prevalence and Predictors of Cigarette Smoking among Secondary School Students in Nigeria.Niger Postgrad Med J.2009; 16(1):40-5

[34]. Haldane J (November 1895). "The Action of Carbonic Oxide on Man". J. Physiol. (Lond.) 18 (5-6): 430-62. PMC 1514663. PMID 16992272. 
[35]. American Thoracic Society(2007),www.thoracic.org.

[36]. Yacoub R, Habib H, Lahdo A, Al Ali R, Varjabedian L, Atalla G, Kassis Akl N, Aldakheel S, Alahdab S, Albitar S (2010). "Association between smoking and chronic kidney disease: a case control study". BMC Public Health 10: 731. doi:10.1186/14712458-10-731. PMC 3004836. PMID 21108832.

[37]. Faucher, Mary Ann. "Factors that influence smoking in adolescent girls: review of the literature." Medscape.com. 2003. (May 2, 2011)http://www.medscape.com/viewarticle/456476_2

[38]. Benowitz, Neal. "The Genetics of Drug Dependence: Tobacco Addiction." The New England Journal of Medicine. Sept. 17, 1992.(April 22, 2011)http://www.nejm.org/doi/full/10.1056/NEJM199209173271210 